\title{
A INSERÇÃO SOCIAL E LABORAL DE GRUPOS VULNERÁVEIS NOS EMPREENDIMENTOS SOCIAIS NO BRASIL POR MEIO DAS COOPERATIVAS
}

\section{Emanuelle Urbano Maffioletti}

Professora Dra. Direito Comercial USP/FDRP

Pesquisadora em Direito Cooperativo

\section{Camila Sato}

Mestre em Direito em Desenvolvimento no Estado Democrático de Direito - USP/FDRP Pesquisadora em Direito Cooperativo

\section{RESUMEN}

El presente estudio aborda sociedades cooperativas cuyo objetivo es la inserción social y laboral de los grupos clasificados como vulnerables en la legislación brasileña. Con ese reto, el estudio contextualiza las políticas públicas existentes en el país con respecto a los grupos vulnerables y las formas de inserción social y laboral, centrándose en medidas normativas e institucionales que fomentan la participación de estos grupos en las empresas sociales. Teniendo en cuenta la dificultad de datos y de investigación cuantitativa sobre las empresas dedicadas al tema, este trabajo trae ejemplos concretos de acciones y agentes, entre ellos cooperativas, que han estado trabajando en la inserción de grupos vulnerables, centrándose en drogadictos y personas con discapacidad. Para ilustrar el escenario problemático observado en Brasil, también se mencionaron ejemplos de cooperativas que actualmente están inactivas, principalmente debido al desafío de la autosostenibilidad de su estructura organizativa.

PALABRAS CLAVE: Cooperativas sociales, empresas solidarias, grupos vulnerables, inserción, inclusión.

CLAVES ECONLIT: I390, J390, Z130.

Cómo citar este artículo/How to cite this article: MAFFIOLETTI, E.U. \& SATO, C.: “A inserção social e laboral de grupos vulneráveis nos empreendimentos sociais no Brasil por meio das cooperativas", CIRIEC-España, Revista Jurídica de Economía Social y Cooperativa, $\mathrm{n}^{0} 36,2020$, pp. 249-272. DOI: 10.7203/CIRIEC-JUR.36.17168. 


\section{THE SOCIAL AND BY WORK INSERTION OF VULNERABLE GROUPS IN SOCIAL ENTERPRISES IN BRAZIL THROUGH COOPERATIVES}

\section{EXPANDED ABSTRACT}

This paper was originally presented at the III Encuentro Internacional de Investigadores Sobre Economia Social, Autogestión y Empleo, that took place in Valencia, September 26 and 27 of 2019. Within the scope of the conference, the researchers had the task of uncovering the real national conditions of solidary enterprises in their respective countries. Despite the need of specific public policies and programs directed to insert vulnerable groups socially and professionally, primarily by solidary enterprises, we verified that the subject is not sufficiently studied and addressed in Brazil.

Considering this context, this paper addresses the cooperative societies that aim to the social and professional insertion of groups classified as vulnerable by the Brazilian legislation. Cooperative societies were the focus of this study, as one of many forms of solidary enterprises, and positively one of the better structured. The first methodologic step consisted in identifying the vulnerable groups, determining who qualified as such and the ambient surrounding them. For this selection and definition of vulnerable groups, the criteria provided by the Brazilian legislation were the initial stepping stones. Then, the research work was on identifying the main stakeholders within the solidary enterprise ecosystem, their initiatives regarding the subject, and possible relationships with public authorities. For this purpose, the study contextualizes the public policies of Brazil concerning vulnerable groups and the forms of social and professional insertion, with emphasis on the legislative and institutional measures that stimulate these groups' participation in solidary enterprises. Combining the identification based on the Brazilian law, as well as the focus on cooperative societies as representative of a solidary enterprise, the Brazilian law n. 9.867/1999, which addresses social cooperative societies was chosen as the framework for the identification of vulnerable groups. Thus, drug addicts and the disabled were identified as vulnerable groups based on the legal criteria mentioned. Concerning what could be considered as social and professional inclusion, insertion into the society and community, the values of labor and autonomy were constant and promoted by the great majority of initiatives found as core elements of importance to the people in vulnerable situation.

When identifying other stakeholders and initiatives regarding the social and professional insertion of vulnerable groups, governmental measures and universities were identified as the primary foundations of their official ecosystem and support actors to the solidary enterprises' network, in addition to the individuals most closely linked to the vulnerable groups. 
However, there was not enough information accessible on public and official channels to provide a complete picture of the solidary enterprises' context in Brazil. Therefore, there was no intention of covering the entirety of the subject, which would require a whole set of governmental effort and investment into compiling all the information regarding solidary enterprises. Considering the lack of formal quantitative data researches regarding the social enterprises who dedicated to this cause, this paper illustrates some concrete examples of entities that operate within the solidary enterprise range, initiatives and players, amongst them being the cooperative society, that have been promoting the insertion of vulnerable groups, with especial attention to drug addicts and the disabled. Despite associations and non-governmental organizations being also mentioned to provide a more complete vision of the study subject, the research spotlight was on cooperatives which main activity is promoting the social and labor insertion of sensitive groups. Because of that, we decided to reunite the information regarding social cooperatives that we located in our study to provide a brief image of the work they develop in Brazil, as well as the difficulties they face. Together with the cooperative societies and some governmental actors, all these organizations compose the constellation of players that provide support for the vulnerable groups identified, promoting their social and professional inclusion.

As indicated by the information gathered, sometimes, labor by itself can represent a form of social inclusion. A great number of people classified as vulnerable does not receive the same opportunities of work, as there is a distinguishable prejudice against their vices and/or disabilities. This hinders them from getting a suitable job position that's, at the same time, able to provide for their livelihood and adequate to their particularities. Therefore, solidary enterprises are a viable alternative, as their initiatives are directly aimed to the particularities of a certain group, providing suitable occupation, unity and support. However, there are not clear or abundant information regarding the participation of public authorities on those initiatives. For some of them, there are data over specific programs that offer funding and training for vulnerable people that fit certain criteria, but even in these cases is not possible to find a complete record of those who were effectively benefited. The data regarding each player, their operation, their stakeholders and their initiatives was found only in third parties' channels, and most of them were poorly informative. Some of the information was also outdated, and there were no recent updates, so that it's not possible to know for sure how or if the initiatives are still unfolding nowadays.

To illustrate the problematic scenario verified on Brazil, examples of inactive cooperative are also mentioned, especially due to the self-sustainability challenge that hangs over their organizational structure. Despite their relevant function on the social and professional insertion of vulnerable groups, we found that the entities of solidary enterprises lack proper institutional support from the specialized government sectors. And as most of them are con- 
stituted by people united by chance and necessity, they not always have the required management skills to maintain a stable organization. In other cases, the absence of sufficient financial support prevents cooperatives societies from building a sustainable organization, crippling their existence. However, these are not the only obstacles: especially considering the cooperatives, it is necessary to have a proper comprehension of their values, principles and structure, as it is a peculiar type of enterprise. Misunderstandings regarding the important role of the cooperative members, for example, make it harder for the cooperative to survive, as its structure depends of its members' work. Those were the main aspects, initiatives, entities, stakeholders, players, and problems identified on this study. However, the subject is greatly bigger, and studying its entirety would not be possible within the scope of this paper. Therefore, we expect to provide a brief view of the Brazilian scenario of initiatives aimed to help vulnerable groups, its failures, obstacles and problems. Further studies would be necessary to deeper explore the subject and provide better alternatives.

KEYWORDS: Social cooperatives, solidary enterprises, vulnerable groups, insertion, inclusion. 


\section{SUMÁRIO}

1. Introdução. 2 Contextualização de políticas institucionais no âmbito da Economia Solidária. 3. Grupos vulneráveis e acesso ao trabalho. 3.1. Dependentes Químicos. 3.2. Pessoas com Deficiência. 4. Rede ESOL em atuação com os grupos vulneráveis. 4.1. Organizações (ONGs) e projetos ESOL. 4.2. Cooperativas Sociais. 5. Conclusão. Referências.

\section{Introdução}

Por ocasiāo de convite de Gemma Fajardo e do Iudescoop para tratar sobre a inclusão social e laboral de grupos vulneráveis por meio dos Empreendimentos Solidários no Brasil no III Encuentro Internacional de Investigadores Sobre Economia Social, Autogestión y Empleo, ocorrido em Valência, nos dias 26 e 27 de setembro de 2019, deparamo-nos com o desafio de realizar uma pesquisa cujos resultados pudessem demonstrar o cenário brasileiro sobre o tema.

Embora haja o reconhecimento acerca da necessidade de implementação de programas públicos e medidas especialmente direcionadas à inserção sócio-laboral dos que se classificam por "grupos vulneráveis" em empreendimentos solidários, o tema não é vastamente tratado no Brasil. Ao contrário, dispóe-se de poucas informaçóes e estatísticas oficiais desatualizadas a ilustrar, de forma falha, o cenário institucional existente a apoiar os referidos grupos, como analisado nesse estudo.

O desafio inicial desta pesquisa foi, então, identificar, dentro dos limites metodológicos existentes, os grupos vulneráveis reconhecidos pelo legislador brasileiro, e a rede formal de protagonistas atuantes nos ecossistemas destes grupos. Posteriormente, passou-se ao desafio de seleção dos grupos vulneráveis e a identificação do ecossistema. A seleção dos grupos deu-se, então, a partir das seguintes premissas: a classificação de grupos vulneráveis pela lei no 9.867/1999 (Lei de Cooperativas Sociais); a temática de "saúde" e os indicadores de pesquisa existentes; e a importância do "trabalho" e da "autonomia" como forma de tratamento e de inserção social.

Uma vez escolhidos os grupos vulneráveis e seus os respectivos ecossistemas, passou-se à busca dos atores e das açóes concernentes ao objeto de pesquisa. Esse teve por centro as açóes governamentais, de universidades (pesquisas e projetos de incubação), os serviços de apoio à rede de empreendimentos e os empreendimentos solidários.

Sem a pretensão de esgotar o tema, nem de sistematizar todas as informaçóes e atuações existentes no Brasil, compilamos as informações extraídas das fontes encon- 
tradas e apresentamos, a seguir, o cenário de políticas institucionais nos âmbitos da Economia Solidária como um todo. Em especial, foram abordados os Dependentes Químicos e de Pessoas com Deficiência, e as iniciativas de empreendimentos de economia solidária que integram tal rede formal e que, naturalmente, são voltadas à inserção laboral destes grupos, com enfoque especial às sociedades cooperativas. Por fim, e a título conclusivo, elencamos as principais dificuldades percebidas na estruturação da rede formal e que interferiram na estruturação desta pesquisa.

\section{Contextualização de políticas institucionais no âmbito da Economia Solidária}

No Brasil, em termos gerais, as políticas públicas de Economia Solidária vêm crescendo aos poucos desde 2003 com a criação da SENAES (Secretaria Nacional de Economia Solidária). Tais açóes, segundo apresentam Morais e Menezes (2018, p. 32), resultaram em legislações, em mecanismos de participação direta no funcionamento do Conselho Nacional de Economia Solidária, e no incremento de políticas púbicas de Economia Solidária nos âmbitos dos governos estaduais e municipais.

Tal medida foi sentida em diversas políticas que prestigiaram a democratizaçáo do crédito e das finanças solidárias, que promoveram o ensino, com a capacitação e a formação de agentes voltados à Economia Solidária; o apoio técnico, por meio de projetos de incubadoras; o estímulo à constituição e funcionamento de empreendimentos solidários; e a promoção de comércio justo.

Em relação aos conceitos de "Organizaçôes" e "Empreendimentos Econômicos Solidários", não há um consenso teórico fechado sobre sua definição, suas características e formatos. Morais e Menezes (2018, p. 30) definem Empreendimentos Econômicos Solidários (EESs) como "organizaçôes singulares ou complexas de caráter coletivo, onde os trabalhadores do meio urbano ou rural exercem a gestão coletiva de seus empreendimentos e que podem ou não ter registro legal para a prática de suas atividades econômicas." Seriam exemplos dessas organizaçóes: as cooperativas, associaçóes, empresas auto-gestionadas, redes solidárias e grupos de trocas.

Os mesmos autores citam a contribuição do programa "Plano Brasil sem Miséria" para o movimento, cujo objetivo foi criar oportunidades de desenvolvimento econômico local, ampliar o mercado das micro e pequenas empresas, estimular a formação de empreendimentos cooperativados e apoiar o microempreendedor individual, as políticas de microcrédito e a economia popular e solidária (Morais \& Menezes, 2018, p. 32). 
Entre 2012 e 2015, tem-se o "Programa de Desenvolvimento Regional, Territorial Sustentável e Economia Solidária”. Os principais resultados desse programa foram a expansão de tecnologias sociais apropriadas à economia solidária (ESOL); a formação de trabalhadores, agentes, formadores, multiplicadores e gestores públicos da ESOL; a implantação e consolidação de Bancos Comunitários de Desenvolvimento, Fundos Rotativos Solidários e apoio ao Cooperativismo de Crédito Solidário; a incubação, fomento, assessoramento técnico e apoio a EESs e suas redes e cadeia de produção, da comercialização e consumo; a promoção da adequação das políticas de crédito às exigências e características dos EESs; a promoçấo do acesso às compras governamentais para produtos e serviços da ESOL e a promoção e fortalecimento de feiras, espaço fixos e bases de serviço para comercialização de produtos e serviços da ESOL.

Ademais, houve um programa específico ao segmento dos resíduos sólidos, com o objetivo de amplificar a capacidade organizativa e produtiva do grupo dos catadores. Por fim, não se pode deixar de mencionar o projeto de lei no 4.685/2012, que criou o Sistema Nacional de Economia Solidária e que está em tramitação no Congresso; e após a aprovação na Câmara dos Deputados, se encontra no Senado Federal.

\section{Grupos vulneráveis e acesso ao trabalho}

Para a inclusão social de grupos vulneráveis, a economia solidária propõe o trabalho como uma terapia essencial para a sua saúde, além de um instrumento de inclusão social e de promoção da cidadania (De Oliveira Barreto, Lopes \& Paula, 2013). A "inserçấo laborativa" desempenharia "um papel central na conquista de um sentimento de dignidade social".

Sobre os grupos vulneráveis, poderiam ser mencionadas duas legislaçóes centrais voltadas ao seu ecossistema e à inserção laboral: a lei no 9.867, de 10 de novembro de 1999, a dispor sobre a cooperativa social; e o decreto no 8.163 , de 08 de dezembro de 2013, que instituiu o Programa Nacional de Apoio ao Associativismo e Cooperativismo Social (Pronacoop Social).

Inspirada pela reforma psiquiátrica italiana (lei no 180/1978) proposta pelo médico Franco Basaglia (Damiano, 2007), a proposta de lei de cooperativas sociais tem como escopo a inclusáo social e laboral das pessoas em desvantagem mediante "a organização e gestáo de serviços socio sanitários e educativos"; e "o desenvolvimento de atividades agrícolas, industriais, comerciais e de serviços", nos termos do artigo $1^{\circ}$ da lei no 9.867/1999. 
Assim, a lei brasileira teria também por objetivo a busca por um tratamento mais humanizado do paciente com deficiência mental (Damiano, 2007). Durante seu tratamento, então se almejava sua inserção na vida em sociedade de forma plena, para a qual a ocupação de um posto de trabalho seria um caminho complementar (ISFER, 2018).

As pessoas em vulnerabilidade compreenderiam as pessoas com deficiência física e sensorial; psíquica e mental, as pessoas dependentes de acompanhamento psiquiátrico permanente, e os egressos de hospitais psiquiátricos; os dependentes químicos; os egressos de prisóes; os condenados a penas alternativas à detenção; os adolescentes em idade adequada ao trabalho e situação familiar difícil do ponto de vista econômico, social ou afetivo.

No mais, tais cooperativas devem adaptar o trabalho e a estrutura em função das especificidades do grupo envolvido, incluindo o trabalho, as instalaçóes, os horários e as jornadas. Ademais, deverão realizar programas especiais de capacitação e treinamentos com o escopo de lhes aumentar a produtividade, a independência econômica e social. E como a lei específica é bastante sucinta, as cooperativas sociais são regidas supletivamente pela lei no 5.764/1971, lei geral sobre sociedades cooperativas.

A segunda política institucional mencionada se trata do Programa Nacional de Apoio ao Associativismo e Cooperativismo Social (Pronacoop Social), implementado pelo Decreto no 8.163/2013, cujos princípios envolvem: a participação e inclusão de pessoas em desvantagem, em situação de vulnerabilidade, na sociedade; o respeito à diferença como parte da diversidade humana; e a geração de trabalho e renda a partir da organização do trabalho com foco na autonomia e autogestão.

São objetivos do programa: incentivar a formalização e o fortalecimento institucional dos empreendimentos econômicos solidários sociais em cooperativas sociais ${ }^{1}$ (Secretaria de Trabalho do Ministério da Economia).

1. Decreto no 8.163/2013: Art. 3o São princípios do Pronacoop Social: I - respeito à dignidade e independência da pessoa, inclusive a autonomia individual e coletiva; II - não discriminação e promoção de igualdade de oportunidades; III - participação e inclusão de pessoas em desvantagem na sociedade e respeito pela diferença como parte da diversidade humana; IV - geração de trabalho e renda a partir da organizaçáo do trabalho com foco na autonomia e autogestão; $\mathrm{V}$ - articulação e integração de políticas públicas para a promoção do desenvolvimento local e regional; e VI - coordenação de açốes dos órgáos que desenvolvem políticas de geração de trabalho e renda para as pessoas em desvantagem.

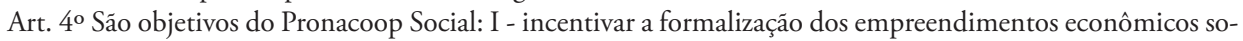
lidários sociais em cooperativas sociais; II - promover o fortalecimento institucional das cooperativas sociais e dos empreendimentos econômicos solidários sociais, e a qualificação e formação dos cooperados e associados; III - promover o acesso ao crédito; IV - promover o acesso a mercados e à comercialização da produção das cooperativas sociais e dos empreendimentos econômicos solidários sociais; $\mathrm{V}$ - incentivar a formaçáo de redes e cadeias produtivas constituídas por cooperativas sociais e empreendimentos econômicos solidários sociais; e 


\subsection{Dependentes Químicos}

A "fragilidade, suscetibilidade e necessidade de proteção adicional" (Bittencourt, França \& Goldim, 2015) faz dos dependentes químicos pessoas vulneráveis e com certas dificuldades de acesso ao mercado de trabalho -seja por preconceito, incompreensão, ou por qualquer outro motivo que mova as pessoas que escolhem excluí-los-, demandando a eles proteção e medidas positivas de apoio.

Acometido pela dependência química, um indivíduo experimentaria uma necessidade contínua de consumir a substância psicoativa, sem a qual não seria capaz de se sentir bem, tampouco de evitar sensações ruins. Passaria, assim, a demonstrar um quadro de sintomas cognitivos, comportamentais e psicológicos que prejudicam seu controle sobre o uso de drogas, mesmo que esteja ciente dos efeitos danosos do hábito (Ministério da Educação, Ministério da Saúde, Secretaria Nacional Antidrogas, 2002).

Além de prejudicar a rotina e a habilidade de conduzir atividades comuns da vida cotidiana, como o trabalho, a depender do tipo de substância consumida, o usuário e o dependente poderiam também se sujeitar a percepçóes sem objeto -vendo, ouvindo, ou sentindo algo que não existe- ou mesmo falsos juízos da realidade, atribuindo significados anormais aos eventos ocorridos ao seu redor. Com esses efeitos, seriam prejudicadas suas funçóes mentais, o que se reflete nos mencionados fenômenos psíquicos anormais (Ministério da Educação, Ministério da Saúde, Secretaria Nacional Antidrogas, 2002).

Estima-se que 5,7\% da população do Brasil seria de dependentes químicos, índice que representaria mais de oito milhóes de brasileiros (Levantamento Nacional das Famílias dos Dependentes Químicos da Universidade Federal de São Paulo, 2013). Além dos adultos, a dependência química é um dos maiores problemas encontrados na infância e adolescência no Brasil, trazendo consigo problemas relacionados à exploração sexual, prostituição, tráfico de droga, inserção precoce e desacompanhada no mercado de trabalho e morte.

Segundo a Organização Internacional de Saúde, 25\% das mortes de jovens entre 15 e 19 anos são atribuídas ao álcool. Segundo a UNICEF, de 206,1 milhóes de brasileiros, 20,5 milhôes são adolescentes e 37,1 milhóes crianças. E 1,59 milhóes de adolescentes de 15 a 17 anos estão fora da escola (IBGE, 2015). Por fim, a cada dia 31 crianças e adolescentes são assassinados por dia no Brasil (UNICEF) (Fonseca, Sena, Santos, Dias \& Costa, 2013).

VI - monitorar e avaliar os resultados e alcances sociais e econômicos das políticas de apoio ao cooperativismo e ao associativismo social. 


\subsubsection{Política institucional}

Para a inclusão social de dependentes e usuários de drogas e álcool, a economia solidária propóe o trabalho como uma terapia essencial para a sua saúde mental, além de um instrumento de inclusão social e de promoção da cidadania (de Oliveira Barreto et al., 2013), e a "inserção laborativa" desempenharia "um papel central na conquista de um sentimento de dignidade social".

Pelas organizaçóes e os empreendimentos solidários, promove-se o treinamento para a obtenção de habilidades que os tornem aptos a conseguir e a manter seus postos de trabalho. Ainda proporcionando uma fonte lícita de renda e melhorando sua autoestima, contribuindo para a redução do abuso de drogas e da prática de atividades criminais (Bonadio \& Silveira, 2013).

Além da inserçáo laborativa como terapia e instrumento de inclusão social proposta pelas organizaçóes solidárias, tem-se algumas medidas legislativas a estabelecer a base da política nacional de drogas. Nesse sentido, pertinentes a lei no $11.343 / 2006$, que institui o sistema nacional de políticas públicas sobre drogas; e o decreto $\mathrm{n}^{\circ}$ 9.761/2019 (Política nacional sobre drogas). Em relação às crianças e adolescentes, existe, ainda, o Estatuto da Criança e do Adolescente, lei no 8.068/1990. Esses programas, em síntese, estabelecem as bases de direitos, apoio terapêutico, acolhimento, reinserção social, prevenção e de capacitação continuada. E, no caso da criança e do adolescente, medidas tutelares (Secretaria Especial do Desenvolvimento Social, 2019).

Em termos de políticas estaduais voltadas à reinserção socio-laboral dos dependentes químicos, são as mais representativas a lei estadual no 7.865/2017 do Alagoas, que estabelece quotas nos contratos celebrados entre a administração pública e as empresas privadas; a lei no 5.757/2016, do Distrito Federal, que estabelece um mínimo de $1 \%$ das vagas de trabalho devem ser destinadas à aos pacientes de instituição pública cadastrada perante o Centro de Atenção Psicossocial; e o Programa Selo Recomeço do Estado de São Paulo (Decreto 60.455/2014), que tem por objetivo estimular os projetos e as açóes socio-laborais de dependentes químicos (inclusive menores de idade) com instituiçôes públicas, privadas e do terceiro setor. Com mais 50 unidades composta por equipe multidisciplinar, este projeto investe nas atividades realizadas durante o atendimento aos dependentes e a seus familiares para a sua recuperação (Confederação Nacional dos Municípios, 2017).

Apresentado o panorama geral do contexto em que se inserem as políticas voltadas aos dependentes químicos no Brasil, cumpre-se abordar outro grupo em situação de vulnerabilidade que também se beneficia da atuação de sociedades cooperativas. 
(pp. 249-272)

\subsection{Pessoas com Deficiência}

As barreiras existentes para as pessoas com de deficiência física ainda são grandes no país ${ }^{2}$, estimando-se que há $6,7 \%$ de brasileiros com deficiência (IBGE, 2018). Atualmente reconhecida sua aptidão ao trabalho e altivez no seu processo de desenvolvimento sem que isto represente uma agressão à sua condição, a abordagem atribuída ao tema no Brasil ainda oscila entre os paradigmas da institucionalização; a sua capacitação para que possam acompanhar as exigências externas; e suporte-inclusão, ou seja, capacitá-los e incluí-los de maneira assistida (Carretta, 2004). A abordagem ideal, assim, seria a de estimular progressivamente o trabalho autônomo, a integração com a coletividade e o aproveitamento de suas habilidades em tarefas parciais e complementares de acordo com as suas competências ${ }^{3}$.

\subsubsection{Politica institucional}

A partir do século XIX, mudanças foram operadas na orientação em relação ao tema da pessoa com deficiência no mercado de trabalho, graças aos exemplos internacionais (Instituto Técnico Industrial na Alemanha, 1822, e Goodwill Industries em Boston, em 1907) e aos marcos internacionais (recomendação internacional da OIT de 1981; e declaração internacional da ONU de 1955, conclamando o trabalho para as pessoas com deficiência física) (Simonelli, 2009).

Tiveram importante contribuição para o Brasil a atuação de instituiçôes não governamentais e o envolvimento da sociedade sobre o tema a partir de 1970, incluindo pessoas com deficiência, Universidades e órgãos públicos, como o Ministério Público, dentre outros. Outros exemplos de programas nacionais e de marcos legais incluem os programas federais profissionalizantes instituídos a partir da década de 70, como o SENAI (Serviço nacional de aprendizagem industrial) e o SENAC (Serviços aprendizagem comercial); SESI, Posto de Amparo ao Trabalhador e Fundo de

2. Apesar das diversas nomenclaturas e correntes existentes para denominar o grupo (como portadores de necessidades educacionais especiais ou portadores de direitos especiais), neste trabalho adotamos "pessoa com deficiência", conforme previsto na legislaçáo e na convenção internacional de proteção e promoção dos direitos de dignidade das pessoas com deficiências da ONU 2003 (ONU).

3. A progressão do movimento e das políticas institucionais trouxe mudanças na abordagem de tratamento do tema. Na década de 70, trabalhava-se com a normalização dos deficientes - ou seja, capacitá-los para deixá-los mais próximos das exigências externas - organizando-se oficinas pedagógicas ou terapêuticas profissionalizantes que ocupavam os deficientes de forma diferente aos demais (com atividades, horários e salários reduzidos), já que eles tinham certas limitaçóes. Depois, abriu-se a outro paradigma, o de aproveitar a capacidade segundo os diversos tipos de atividades, dando o suporte necessário por meio de instituiçóes e de educação da sociedade (paradigma de suporte-inclusão) (Caretta, p. 43-44). 
Amparo ao Trabalhador; centros de reabilitação profissional do Instituto Nacional de Previdência Social, nas grandes capitais Brasileiras, para readaptação profissional.

Ainda, existem programas municipais-estaduais profissionalizantes. Previsto na portaria no 964/2018, o Centro de Convivência e Cooperativa (CECO), com mais de 20 anos de existência, implementa serviços precursores da reforma psiquiátrica na cidade de São Paulo. Sendo um espaço de convivência entre pacientes que apresentam transtornos mentais, deficiências, idosos, crianças e adolescentes em situação de vulnerabilidade social e de saúde, cujo principal objetivo é proporcionar a reinserção social e integração no mercado de trabalho (Secretaria Municipal da Saúde).

Também são referências normativas relevantes sobre a matéria: (a) a lei $\mathbf{n}^{\mathbf{o}}$ $8.213 / 1991$, que estabelece quotas de vagas reservadas à pessoas com deficiência para empresas privadas - entre 100 a 200 funcionários, $2 \%$ de vagas reservadas; 201 a 500 funcionários, 3\% de vagas reservadas; e 501 a 1000 funcionários, $4 \%$ das vagas reservadas; e acima de 1001 funcionários 5\% de vagas reservadas; e (b) o decreto-lei no 3.298/1999, ao dispor sobre política nacional para integração social e econômica da pessoa com deficiência, com inserção socio-laboral por cooperativas.

\section{Rede ESOL em atuaçáo com os grupos vulneráveis}

Não foram encontradas informaçóes completas ou atualizadas a respeito dos empreendimentos solidários voltados aos grupos vulneráveis ora abordados, e algumas circunstâncias interferiram negativamente no mapeamento oficial dos empreendimentos solidários no país e, por consequência, nos resultados compilados nessa pesquisa. São elas: o limitado orçamento, com a redução de custos orçamentários entre 2016 e 2019 de aproximadamente 85\% (Silva, 2018); o contexto político e econômico do Brasil; a mudança no SENAES, que, depois de 2018, se tornou uma subsecretaria ligada diretamente ao gabinete do Ministro do Trabalho; e, por fim, o fato de que grande parte dos empreendimentos sociais ainda são informais.

Como menciona Silva (2018), após o momento de inserção e consolidação das políticas de Economia Solidária (mencionados no primeiro item deste trabalho), chegou-se ao momento de crise, ameaçando a continuidade das políticas da Economia Solidária no Brasil. Para demonstrar esse cenário, o último mapeamento formal foi realizado em 2013. Nele, do total de $19.708 \mathrm{EESs}$, ainda predominam as associaçóes como forma de organizaçáo, correspondendo a 11.823 das EESs. Além disso, grupos informais ainda representam grande parcela das EESs, em 6.018 organizaçóes, correspondendo as cooperativas a 1.740 das EESs mapeadas. 
E, ainda, para que se tenha uma ideia sobre a divergência das informaçóes, sobre os grupos vulneráveis, foi consultado o sistema RAIS (Relação Anual de Informaçóes Sociais) por meio do Observatório Nacional da Economia Solidária e do Cooperativismo do ano de 2013 (Departamento Intersindical de Estatística de Estudos Socioeconômicos). Nele, constam somente 4 empreendimentos que exercem as "Atividades de assistência psicossocial è à saúde a portadores de distúrbios psíquicos, deficiência mental e dependência química e grupos similares não especificadas anteriormente" (CNAE específico: 8720-4/99) cadastrados formalmente, sendo um no Ceará, um em Minas Gerais, um no Rio Grande do Sul, e um em São Pauló .

A seguir, serão apresentados alguns exemplos de empreendimentos solidários coletados nesta pesquisa, ressalvando os limites metodológicos existentes, que dizem respeito à limitação e informalidade de certas informaçóes, as quais raramente se encontraram disponíveis em sua integralidade.

\subsection{Organizaçóes (ONGs) e projetos ESOL}

Por meio dos empreendimentos solidários, promove-se o treinamento para capacitar as pessoas com deficiência, auxiliando-os na seleção e manutenção dos postos de trabalho, além de contribuir com a melhora de sua autoestima, com a redução do abuso de drogas e da prática de atividades criminais (Bonadio \& Silveira, 2013). No Brasil, as organizaçóes não governamentais são numerosas e ativas, com destacada colaboraçáo no processo de inserção social dos grupos vulneráveis, apesar das limitaçóes institucionais e econômicas. Como não é o escopo do presente trabalho, mencionaremos apenas alguns exemplos de organizaçóes e projetos para elucidar os protagonistas atuantes nos ecossistemas.

A APAE é uma das maiores associaçóes do país voltada às pessoas com deficiência e possuem alguns cursos de capacitação. É uma organização da sociedade civil, sem fins lucrativos, que previne e promove a saúde das pessoas com deficiência intelectual, apoia sua inclusão social, incide na defesa de seus direitos, produzindo e disseminando conhecimento.

Distribuída ao longo do país, a unidade de São Paulo conta um programa de grande efetividade na inclusão e permanência profissional das pessoas com deficiência intelectual, provendo o apoio técnico no próprio local de trabalho por, pelo menos, 12 meses. Com programas customizados, a APAE de São Paulo é uma entidade formadora para a aprendizagem profissional regulamentada no ministério do

4. https://observatorios.dieese.org.br/ws2/tabela/economia-solidaria/numero-de-estabelecimentos-de-economia-solidaria-na-rais-por-cnae. 
trabalho. Seu processo inclui: análise de postos de trabalho, palestras de sensibilização, diagnóstico clínico, indicação de pessoas, qualificação profissional e acompanhamento pós-inclusão.

A Associação de Prevençáo e Assistência aos Dependentes de Drogas (APADD) volta-se aos dependentes de drogas em Vila Velha, Espírito Santo. Atua na assistência semanal com equipe multidisciplinar, no acompanhamento por assistente social e curso de capacitação para ingresso no mercado de trabalho; e na formação de profissionais para atuar no campo da dependência de drogas, com entendimento sobre o trabalho preventivo, o tratamento, a reinserção social e também com abordagens.

Outro exemplo é a ONG Salve a Si, voltada ao acolhimento dos dependentes químicos. Como algumas de suas açóes, mencionamos a recuperação e reinserção socio-laboral dos dependentes, o tratamento sistêmico dos dependentes e codependentes, e o apoio aos familiares. Localizada em Cidade Ocidental, Goiás, desde 2008, essa organização já acolheu mais de 2000 pessoas em situação de vulnerabilidade social e seus familiares. Com capacidade de receber até 120 dependentes, a ONG dispóe de oficina de marcenaria e de uma estação digital de metarreciclagem, havendo também planos para a construção de uma fábrica de tijolos ecológicos.

Não se pode olvidar, ainda, da UNICEF, cuja relevância é reconhecida pelo governo e parceiros no Brasil. Atuando com crianças e adolescentes, o seu trabalho está voltado à assistência, educação e promoção dos direitos. Muitas outras ONGs atuam com este grupo, embora não sejam voltadas ao mercado de trabalho, mas, sim, à educação.

Por fim, também contribuem para o movimento as organizações que integram o projeto de incubadoras tecnológicas de cooperativa popular. Trata-se de projeto acadêmico integrado por diversas Universidades do país com o objetivo de discutir e colaborar com a formaçáo de empreendimentos solidários, inclusive capacitando-os. Alguns destes projetos são voltados aos grupos vulneráveis.

A Incubadora Tecnológica de Cooperativas Populares da Universidade Federal do Rio de Janeiro (ITCP/UFRJ), por exemplo, surgiu em 1995 e tem gerado importantes empreendimentos solidários auto gestionários para indivíduos e grupos em situação de vulnerabilidade social e econômica. Esta incubadora tem projetos importantes voltados à consolidação dos empreendimentos de rede de saúde mental, inserção pelo trabalho e economia solidária em parceria com o governo, além do apoio a várias cooperativas.

Um segundo exemplo é o da Incubadora de Cooperativas Populares de Autogestáo da Universidade Federal do Ceará (UFC), fundada em 1997, e que conta com o apoio do Governo do Estado do Ceará. Inicialmente voltado à capacitação de jovens moradores de periferia pelo oferecimento de cursos profissionalizantes, em 2004 a 
incubadora iniciou o projeto "Cooperativas Sociais" com o intuito de dar oportunidade aos egressos dos Centros de Atendimento Psicossocial (CAPS), ex-dependentes químicos, e outros (Adital, 2010).

\subsection{Cooperativas Sociais}

Ainda com a proposta de identificar a rede formal de protagonistas atuantes nos ecossistemas dos grupos vulneráveis de dependentes químicos e pessoas com deficiência, nos concentramos agora nas cooperativas sociais que atuam com estes grupos dentro da abordagem de inserção laboral.

Especificamente em relação às cooperativas sociais, tem-se que se classificam nos seguintes grupos: o que trabalha com educadores, assistentes sociais, enfermeiros, cujos públicos são pessoas com deficiência, idosos, menores de idade e dependentes químicos, tendo como atividades principais prestação de saúde, educação, entre outras; e o que trabalha com a inclusão social de pessoas desfavorecidas, como desempregados, mendigos, entre outros. As atividades principais desenvolvidas por este tipo de cooperativa são a reciclagem de lixo, artesanato, limpeza, entre outras (Matias, 2004).

Seguindo os ensinamentos de Carretta (2005, p. 2), o foco da pesquisa foi a busca de modelos de empreendimentos que estimulam a capacitaçâo e autonomia de tais sujeitos, em paralelo às assistências. Nesse aspecto, os modelos cooperativos abertos à inserção de tais sujeitos como cooperado "assistido" corresponderiam mais ao ideal buscado, pois a autonomia permite o desenvolvimento dos agentes envolvidos e interrompem a situação de dependência ou hierarquia, fazendo-lhes autores da própria vida.

\subsubsection{Cooperativas de dependentes quimicos}

Sobre as cooperativas ativas cuja atividade é a inserção sócio laboral de dependentes químicos, foram localizadas em nossas pesquisas apenas duas. A primeira delas é a Cooperativa Social de Dependentes Químicos em Recuperação (COREDEQ), constituída em 2017 em Maceió, Alagoas. O seu objetivo é a reinserção no mercado de trabalho de jovens e adultos com dependência química, prestando também atenção especial aos seus familiares. Para tanto, a cooperativa dispóe de núcleos de trabalho específicos, os quais se centram em objetivos diversos: ocupação e renda, atenção aos moradores de rua, projeto REINSERIR, Justiça Terapêutica e Núcleo Administrativo e Financeiro da COREDEQ (Alagoas 24 Horas, 2018). 
Um segundo exemplo seria a Cooperativa Rainha da Reciclagem constituída em 2016, em Sáo Paulo. Nessa cooperativa, o objetivo final seria a reciclagem de lixo com o intuito de custear atividades caritativas. Assim, a cooperativa proporciona acolhimento e tratamento dos dependentes químicos; com atendimento a homens e mulheres, tendo como foco as mulheres de rua, contribuindo no combate à prostituição e ao tráfico. $\mathrm{Na}$ medida em que a cooperativa realiza a troca materiais recicláveis por comida, oferece a essas pessoas em situação de vulnerabilidade uma alternativa para sua sobrevivência, permitindo-lhes outra saída que náo o tráfico ou a prostituição.

As finalidades a que se presta essa cooperativa têm profunda relação com a experiência de vida pessoal de sua fundadora, Elinéia Gomes de Jesus, que, após sair da prisão, decidiu montar esse projeto para ajudar os dependentes químicos. A ideia nasceu da venda de balas nos sinais por 18 dependentes químicos. Atualmente, a receita da cooperativa é de $\mathrm{R} \$ .18 .000$ reais por mês, e os cooperados ganham cerca de $\mathrm{R} \$ .800,00$ e pagam o INSS (pensão). A cooperativa processa, aproximadamente, 50 toneladas de resíduos por mês e em 2018 havia 12 cooperados (Reciclasampa).

Com escopos coincidentes, tais cooperativas sociais são relativamente recentes, mas, segundo as informações obtidas, ainda estão ativas e com projeto de crescimento. Ainda, ambas aparentam estar articuladas com outros sujeitos e projetos, com o propósito de promover a atividade e obter os necessários recursos financeiros.

\subsubsection{Cooperativas dedicadas às pessoas com deficiência}

Em relação às cooperativas dedicadas às pessoas com deficiência, foram encontradas quatro cooperativas. Um primeiro exemplo seria a Cooperativa Praia Vermelha, constituída em 1997, no Rio de Janeiro, que surgiu da parceria entre usuários, familiares e técnicos de serviços públicos de saúde mental do Instituto Philipe Pinel e a equipe da Incubadora Tecnológica de Cooperativas Populares da COPPE/ URFJ. Desta cooperativa, e do apoio de incubadora, surgiu A Cooperativa Papel Pinel, constituída em 2000, no Rio de Janeiro. Esta promove a inclusão social e laboral pela produção de papel artesanal que se transforma em cadernos, blocos e cartóes personalizados com ilustraçóes ou colagens dos artistas do Projeto, que com originalidade também criam camisetas, bolsas, mochilas, ecobags e logomarcas originais.

Seu objetivo abarca a reabilitação de pessoas com deficiências mentais, com geração de trabalho e renda visando a superar o preconceito e promover a inclusão social. Os integrantes da cooperativa fabricam pães, bombons, biscoitos e bolos com produtos extraídos da Amazônia de maneira sustentável. Depois da produção, partem 
para a venda em empresas e projetos. O dinheiro arrecadado é dividido entre quem vende e quem produz, e parte é destinada à compra de material (Rede Mobilizadores, 2010).

O projeto da Cooperativa Praia Vermelha está inserido dentro de uma rede de entidades que se propóe a pensar e implementar alternativas para o ingresso de pessoas com transtornos mentais no mercado de trabalho. Com freguesia assídua no campus da Praia Vermelha, os produtos da Cooperativa Praia Vermelha vêm se destacando pela qualidade. Na cooperativa, as pessoas com transtornos psíquicos encontraram um espaço que náo é meramente terapêutico. Com 11 anos de fundação, a cooperativa já atendeu cerca de 100 usuários dos serviços de saúde mental (Rede Mobilizadores, 2010).

Importante mencionar também a Cooperativa Social de Pais, Amigos e Portadores de Deficiência, COEPAD, constituída em 1999, Santa Catarina, que visa a capacitação e o trabalho a pessoas com deficiência intelectual, promovendo a inclusão social e laboral com o apoio da OCESC, a Organizaçáo das Cooperativas do Estado de Santa Catarina. A respeito de sua história, foi produzido, inclusive, um documentário intitulado "Fibra", o qual tem como centro as "relaçóes de amizade entre Fabiana Brito, Luciano Ramos e Angélica Medved, todos com sindrome de Downe cooperados da Coepad'. O documentário venceu o Prêmio Júri Oficial de Melhor Filme na Mostra Catarinense do FAM (Florianópolis Audiovisual Mercosul) e ganhou, no mesmo festival, o Prêmio Itapema FM de melhor filme (COEPAD, 2019).

As oficinas construídas pela COEPAD oferecem diversos tipos de capacitação a seus cooperados, como corte e costura, cartonagem, papel artesanal, acabamento gráfico e serigrafia. Do aprendizado e do trabalho dos cooperados resultam diversos produtos de papelaria e camisetas, disponível para compra no sítio eletrônico da cooperativa, e cujos recursos são revertidos para sua manutenção.

Por fim, também merece ser mencionada a Cooperativa de Trabalho Social de Profissionais Especiais - Cooper Social, surgida em 1994, no Rio Grande do Sul. O Painel Sensorial (olfativo) é um dos principais projetos da Cooper Social e está associado a duas grandes indústrias do ramo de cosméticos e perfumaria: 15 deficientes visuais "emprestaram" seu olfato para a análise e avaliação das fragrâncias quanto à intensidade, volatilidade e outros itens importantes para os produtos que seriam fabricados.

Dentre essas cooperativas, percebe-se que certos projetos surgem de incubadoras e de centros de saúde dentro de hospitais. Assim, verifica-se que nesses modelos há o envolvimento dos pacientes, em benefício à melhoria significativa de seu quadro clí- 
nico. Outras cooperativas surgem a partir de oportunidades identificadas pelos próprios familiares das pessoas com deficiência, contribuindo mesmo para a indústria.

Em termos de sustentabilidade do projeto, embora não se tenha informaçóes precisas, percebe-se pelo histórico das cooperativas identificadas que aquele é fortalecido em função da proximidade existente com outros atores, dentre os quais o Estado. Ainda, existe uma certa flexibilidade dos objetos sociais prestados, muitos dos quais acumulam atividades diversas.

\subsubsection{Outros exemplos de modelos encontrados}

Além do modelo cooperativo, localizamos a Associação Central de Assistência, serviços e apoio à deficientes físicos de Botucatu, que foi constituída em 1999, em Sáo Paulo. Trata-se de um exemplo de estrutura que náo adota a forma de cooperativa, mas que se apresenta como modelo cooperativo por seguir os seus princípios, conforme relatado por Carretta (2004, p. 86).

O objetivo envolve a capacitação e o ingresso ao mercado de trabalho de deficientes físicos, mentais, visuais e auditivos. A ideia de sua constituição é proveniente de Fernando Douglas Angela, presidente e pessoa com deficiência em virtude de acidente de trabalho. Após a edição da Lei n. 8.213/1991 (que prevê a contratação de Pessoas com Deficiência), ele intermediou a contratação, conseguindo 12 empregos formais com condições especiais como carro adaptado, flexibilidade de horário e transporte em caso de emergência. Contudo, os demais funcionários começaram a reivindicar as mesmas condiçóes de trabalho dos deficientes, levando ao encerramento do projeto.

A partir disto, Fernando constituiu uma sociedade de multisserviços -aproveitando o potencial dos cooperados e as lacunas do mercado (a exemplo dos resíduos sólidos) para comercializar seus produtos- e uma associação. A intenção era formar uma cooperativa de trabalho, mas o modelo se mostrou inviável pelo fato de muitos cooperados receberem aposentadoria e não poderem ser membros dessa sociedade. Assim, embora "adote" a organização de cooperativa de multisserviços, no que toca a distribuição da remuneração, a estrutura organizacional formal é outra.

O projeto continua ativo, recebendo adolescentes encaminhados pelo conselho tutelar e desempregados em busca de qualificação profissional. Assim, há pacientes que se beneficiam da assistência e outros que prestam serviço à "sociedade". Junto à comunidade, esse grupo promove os direitos dos deficientes -envolvendo discussóes de cidadania- e arrecada dinheiro, além de atuar junto aos órgãos da comunidade e na orientação dos direitos. 
Enfim, pode-se dizer que o modelo híbrido traria mais flexibilidade organizacional, financeira e de articulação com outros sujeitos. Uma questáo que continua aberta diz respeito à confusão com o modelo cooperativo e a autonomia dos "cooperados", já que, em termos de estrutura societária, os modelos são bastante distintos.

\subsubsection{Cooperativas com aparente inatividade}

A seguir, apresentam-se o exemplo de três cooperativas que aparentemente não estão ativas, porém, que merecem ser mencionadas para elucidar o cenário problemático dessas organizaçóes o Brasil. A primeira cooperativa é a Maria Flor, cooperativa de deficientes intelectuais que se dedicava à inserção laboral. Foi constituída por 6 mães de ex-alunos da APAE e, infelizmente, passou por dificuldades financeiras. Atualmente, só é possível encontrar informaçóes no perfil online da plataforma facebook, mas a página oficial está inativa e também o cadastro de pessoas jurídicas.

Um segundo exemplo é o da Cooperativa de produçáo industrial dos profissionais em confecção e trabalho artesanal a trama da arte - TRAMART, constituída em 1999, em São Paulo. Trata-se de uma cooperativa de artesãos com e sem deficiência no Estado de São Paulo a promover a capacitação para o trabalho com cursos gratuitos para desenvolvimento do conhecimento técnico em artesanato as pessoas sem experiência que desejam entrar no quadro; bem como das funçóes administrativas, como a formação de equipes de compra, venda e contabilidade.

A cooperativa foi constituída por Erika Alvarinho e por um grupo de 15 pessoas, professores de artesanato, com o objetivo de produzir e comercializar os seus produtos. Sem um período de incubação do projeto, nem uma assessoria técnica inicial, o grupo participou do Programa Educação Cooperativista e o Portador de Deficiência, promovido pela Secretaria de Emprego e Relaçóes do Trabalho. O projeto contou com o apoio financeiro do Programa Comitê de Entidades Públicas no Combate à fome e pela Vida, que foi destinado à aquisição de maquinários e material, além de funcionários.

A cooperativa dispunha de reunióes mensais com os cooperados e de um regimento interno. Nas reunióes, discutiam-se assuntos gerais e específicos (por grupos técnicos) sobre a realização da atividade e planejamento. De cada peça vendida, 10\% era destinado à cooperativa e 50\% era reinvestido na cooperativa (Carretta, 2004, p. 76). Havia três diretores, além do conselho fiscal e eventuais consultas a uma assessoria externa, e os cooperados tinham direito a férias de 30 dias ao ano

A cooperativa conseguiu atingir o objetivo esperado, com a proposta de possibilitar maior autonomia às pessoas com deficiência dentro do processo de trabalho 
e maior apropriação do processo de trabalho, embora atualmente esteja inativa. Algumas razóes foram identificadas por Carretta (2004, p. 76) como: a falta de apoio técnico e de conhecimento de gestão dos administradores; falta de governança; a falta de comprometimento por parte dos cooperados em relação à execução do trabalho; as retiradas de certos cooperados; o fato de não terem uma remuneração constante; mudanças constantes de sede; desintegração social; a definição de artesanato como objeto social a limitar a integração de novos interessados no projeto, embora a cooperativa tenha informado posteriormente que poderia receber novos cooperados de forma gratuita.

Por fim, menciona-se a Cooperativa Padro Vicente de Paulo Penido Burnier - Copavi, de Belo Horizonte. Com atividades voltadas à inserção no mercado de trabalho, a cooperativa oferece serviços de digitação; curso de língua dos sinais; educação cooperativista; e orientação ao trabalho. Contudo, a capacitação não pôde ser viabilizada pela escassez de recursos financeiros.

Com 24 fundadores, a Cooperativa foi constituída para se dedicar à capacitaçáo das pessoas com deficiência auditiva para que tenham a oportunidade de produzir e ter renda. Assim, além de pessoas com deficiência, havia os sem deficiência, que atuam em serviços específicos em auxílio às pessoas com deficiência, por exemplo, na negociação.

Diversos foram os problemas a atingir a cooperativa, contudo, como a falta de recursos financeiros e de sede, falta de capacitação administrativa, falta de compreensão do que é cooperativa, a excessiva proteção familiar a obstaculizar o desenvolvimento laborativa, falta de colaboração e de orientação sobre as obrigações. Assim, a cooperativa foi fechada em 2003.

\section{Conclusáo}

O desafio inicial desta pesquisa foi identificar, dentro dos limites metodológicos existentes e a partir dos grupos vulneráveis reconhecidos na lei brasileira, a rede formal de protagonistas atuantes nos ecossistemas destes grupos. Como pano de fundo, tem-se a importância do fomento e da articulaçáo entre os atores para o fortalecimento e autonomia dos empreendimentos solidários que se destinam à sua inserção sócio laboral (Morais \& Menezes, 2018). Assim, foram abordados os dependentes químicos e pessoas com deficiência, analisando a sua inserçáo laboral promovida por cooperativas, tendo-se identificado também outros tipos de organizações, como associações. 
Como se pode verificar, o número de empreendimentos solidários informais ainda é significativo no Brasil, inclusive superando o número de cooperativas regulares. Além disto, não há um sistema de dados atualizado e os atores nem sempre dispóem de recursos ou interesse de se profissionalizar e disponibilizar informaçóes públicas.

A respeito das cooperativas, foco da pesquisa, verificamos que aquelas mapeadas trazem os seguintes indicadores: a importância de incubadoras com o escopo de formar o grupo com os princípios cooperativistas; a ausência de assistência técnica (contábil, financeira, legal, técnica e psicológica); a deficiência de profissionalismo e de empreendedorismo das cooperativas e que precisam sem mais estruturadas; a escassez de recursos financeiros; o necessidade de fortalecimento de políticas públicas e de sistema de rede. Nota-se, ainda, que açóes educativas são importantes para a consolidação do modelo, pois falta interesse por parte dos grupos vulneráveis, seus familiares e da coletividade.

Por fim, conclui-se que os tais modelos ainda carecem de autossustentabilidade na sua concepção e desenvolvimento, demandando o apoio da iniciativa privada e pública e a articulação dos atores em rede. 


\section{Referências}

ADITAL: "Incubadora da UFC estimula o cooperativismo há mais de dez anos", Ceará, Portal Vermelho, 6 março 2010, recuperado em 6 setembro 2019. http://www.vermelho.org.br/noticia/125199-1, 2010.

BITTENCOURT, A.L.P., FRANÇA, L.G. \& GOLDIM, J.R.: "Adolescência vulnerável: fatores biopsicossociais relacionados ao uso de drogas", Revista Bioética, $n^{\circ}$ 23(2), 2015, pp. 311-319.

BONADIO, A.N. \& SILVEIRA, C.: "Economia solidária e reabilitação vocacional no campo da drogadição: possibilidades e limites das práticas atuais", Saúde e Sociedade, no 22, 2013, pp. 99-108.

CARRETTA, R.: Pessoas com deficiência organizando-se em cooperativas: uma alternativa de trabalho?, Tese (Doutorado em Engenharia de Produção) - Universidade Federal de São Carlos, São Carlos, 2004.

CONFEDERAÇÃO NACIONAL DE MUNICÍPIOS - CNM: Leis e Programas Nacionais e Internacionais de Reinserção de Dependentes Quimicos no Mercado de Trabalho, Brasília, CNM, 2017

COOPERATIVA SOCIAL DE PAIS, AMIGOS E PORTADORES DE DEFICIÊNCIA - COEPAD: "Documentário Fibra", recuperado em 6 agostos 2019 de http://www.coepad.com.br/.

DAMIANO, H.: "Cooperativas sociais", Revista do Tribunal Regional do Trabalho da 15a Regiäo, no 31, 2007.

DE OLIVEIRA BARRETO, R., LOPES, F.T. \& DE PAULA, A.P.P.: “A economia solidária na inclusão social de usuários de álcool e outras drogas: reflexôes a partir da análise de experiências em Minas Gerais e São Paulo", Cadernos de Psicologia Social do Trabalho, no 16(1), 2013, pp. 41-56.

DEPARTAMENTO INTERSINDICAL DE ESTATÍSTICA DE ESTUDOS SOCIOECONÔMICOS - DIEESE: "Observatório Nacional da Economia Solidária e do Cooperativismo”, recuperado em 6 agosto 2019.

https://ecosol.dieese.org.br

FONSECA, F.F., SENA, R.K.R., SANTOS, R.L.A. et al.: "As vulnerabilidades na infância e adolescência e as políticas públicas brasileiras de intervenção", Revista Paulista de Pediatria, no 31(2), 2013, pp. 258-264. 
INSTITUTO BRASILEIRO DE GEOGRAFIA E ESTATÍSTICA (IBGE): “Pesquisa Nacional por Amostra de Domicílios - PNAD", recuperado em 17 dezembro 2019 de https://www.ibge.gov.br/estatisticas/sociais/trabalho/9127-pesquisa-nacional-por-amostra-de-domicilios.html?=\&t=destaques, 2015.

INSTITUTO BRASILEIRO DE GEOGRAFIA E ESTATÍSTICA (IBGE): "Panorama Nacional e Internacional da Produção de Indicadores Sociais", recuperado em 17 dezembro 2019 de https://www.ibge.gov.br/estatisticas/sociais/populacao/20438-panorama-nacional-e-internacional-da-producao-de-indicadores-sociais.html?edicao=20935\&t=sobre, 2018.

ISFER, E.: "Cooperativas Sociais". In Sociedades Cooperativas (Coord. GONÇALVES NETO, A.de A.), São Paulo, Lex, 2018, pp. 479-50.

LEVANTAMENTO NACIONAL DAS FAMÍLIAS DOS DEPENDENTES QUÍMICOS DA UNIVERSIDADE FEDERAL DE SÃO PAULO - LENAD FAMÍLIA/UNIFESP: "II Levantamento Nacional de Álcool e Drogas (II LENAD)", recuperado em 30 novembro 2019 de https://inpad.org.br/_lenad-familia/, 2013.

MATIAS, B.: "Cooperativismo social é a nova geração de cooperativas no mundo", recuperado em 16 setembro 2019 de https://administradores.com.br/noticias/ cooperativismo-social-e-a-nova-geracao-de-cooperativas-no-mundo, 2004.

MINISTÉRIO DA EDUCAÇÃO, MINISTÉRIO DA SAÚDE, SECRETARIA NACIONAL ANTIDROGAS: Curso técnico - Reabilitação de dependentes quimicos, 2002.

MORAIS, L.P. \& MENEZES, D.F.N: “Economia Social E Solidária (Ess) No Brasil No Século Xxi: Avanços, Limites e Desafios Atuais". In Anuario iberoamericano de la economía social (Coord. ÁLVAREZ, J.F., MARCUELLO, C., MORAIS, L. et al.), n. 3/2018, CIRIEC-España, recuperado em 6 setembro 2019.

http://www.oibescoop.org/wp-content/uploads/Anuario_Iberoamericano_OIBESCOOP_n3_2018.pdf, 2018.

RECICLASAMPA: "Rainha da reciclagem cria cooperativa para recuperar dependentes”, recuperado em 20 agosto 2019 de https://www.reciclasampa.com.br/ artigo/rainha-da-reciclagem-cria-cooperativa-para-recuperar-dependentes.

REDE MOBILIZADORES: "Cooperativa apoia ressocialização de pessoas com transtornos psíquicos", recuperado em 30 novembro 2019 de http://www.mobilizadores.org.br/noticias/cooperativa-apoia-ressocializacao-de-pessoas-com-transtornos-psiquicos/. 
SECRETARIA DE TRABALHO DO MINISTÉRIO DA ECONOMIA: "Associativismo e Cooperativismo social (Pronacoop Social)", recuperado em 6 agosto 2019 de

http://trabalho.gov.br/trabalhador-economia-solidaria/programas-e-acoes/associativismo-e-cooperativismo-social.

SECRETARIA ESPECIAL DO DESENVOLVIMENTO SOCIAL: "Governo federal implementa nova Política Nacional Sobre Drogas", recuperado em 06 setembro 2019 de http://mds.gov.br/area-de-imprensa/noticias/2019/abril/governo-federal-implementa-nova-politica-nacional-sobre-drogas, 2019.

SECRETARIA MUNICIPAL DA SAÚDE - SMS: "Portaria no 964/2018”, recuperado em 10 dezembro 2019 de http://legislacao.prefeitura.sp.gov.br/leis/portaria-secretaria-municipal-da-saude-sms-964-de-27-de-outubro-de-2018.

SILVA, S.P.: "Crise de paradigma?: a política nacional de economia solidária no PPA 2016-2019”, Em mercado de trabalho, no 64, 2018.

SIMONELLI, A.P.: Contribuiçôes da análise da atividade e do modelo social para a inclusão no trabalho de pessoas com deficiência, Tese (Doutorado em Engenharia de Produção) - Universidade Federal de São Carlos, São Carlos, 2009.

SISTEMA NACIONAL DE INFORMAÇÃO EM ECONOMIA SOLIDÁRIA - SIES: "Atlas Digital da Economia Solidária", recuperado em 7 agosto 2019 de http://atlas.sies.org.br.

UNICEF: "Adolescentes", recuperado em 17 dezembro 2019 de https://www.unicef.org/brazil/adolescentes. 